\title{
Study on Interval Prediction and Application of Inter-well Pumping for Low Production and Low Efficiency in Yanchang Oilfield
}

\author{
Yajie Zhao ${ }^{1, a}$, Duanyin Zhu ${ }^{2, b}$, Jingfeng $\mathrm{Liu}^{1, \mathrm{c}}$ and Hua Huang ${ }^{1, \mathrm{~d}}$ \\ ${ }^{1}$ Exploration and Development Technology Research Center of Yanchang Oilfield Company \\ Limited, Yan'an, Shaanxi province, 716500, China \\ ${ }^{2}$ Xi'an Shiyou University, Xi'an, Shaanxi province, 710065, China

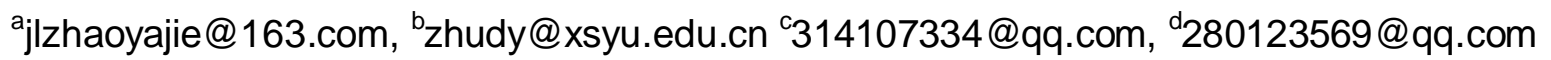

Keywords: Inter-pumping well; Intermittent pumping cycle; Integral method; Application research.

\begin{abstract}
In order to meet the supply and demand balance of ultra-low permeability reservoirs and improve the efficiency of rod pumping system, intermittent pumping wells is a good method. According to the characteristics of Yanchang oilfield low-production and low-efficiency well, analyzing the adaptability of the inter-pumping prediction model in Yanchang oilfield is necessary. The paper discusses the application of the integral method in the inter-pumping working system.
\end{abstract}

\section{Introduction}

Yanchang oilfield is ultra-low permeability reservoirs. The phenomenon of inter-pumping production and insufficient capacity for liquid are appearing among the wells, during the development process. This part of the wells to take all-day exploitation is bound to cause energy waste, so the inter-pumping is an extremely effective way. Inter-pumping is a method by liquid level recovery to overcome the problem that the liquid supply capacity can not meet the working requirements of the oil pumping equipment and it is a simple and practical method to improve the pump efficiency by shortening the running time of the pumping. However, due to the need for a period of time during the liquid level recovery, in this process the pressure in the wellbore is lifting, followed by the differential pressure between wellbore and the formation drop and the amount of seepage reduce. Therefore, how to make the pumping well can run in high efficiency state, and at the same time to release stratigraphic potential as much as possible, is the problem that must be solved to determine a reasonable intermittent pumping system.

The most important thing for oil well pumping mode of production is to determine the reasonable shut-down time and open-well time, that is, the intermittent cycle, and the most direct method to determine it is detecting the variation of the liquid level or sinking degree[1-7]. Based on the characteristics of Yanchang oilfield the low-production and low-efficiency wells, the variation law of oil production and fluid production in wellhead is analyzed qualitatively. In order to further optimize the inter-pumping work system and improve the effect of the inter-pumping energy-saving, the paper carried out the field test research on the optimized working system of the inter-pumping well.

\section{Intermittent Pumping Cycle Prediction Model.}

The determination of intermittent cycle is influenced by various factors such as stratum, fluid and working system, and the relationship between the factors is intricate. In order to determine the intermittent cycle, a variety of inter-pumping cycle prediction model appeared.

Grey Model. Think of the entire production wells as a system and use systematic engineering theory to solve the problem. The variation rules of the dynamic fluid level of wellbore directly determines the period of scientific intermittent cycle, while the dynamic fluid level reflects less the types of information. Therefore, using the Gray System Theory, the "small sample" and "poor 
information" uncertain system with "partial information known and partial information unknown" as research object, to study the production system of the inter-pumping well. Grey prediction is the most important part of the gray system theory. The most common one is the GM $(1,1)$ model $[8,9]$.

The method has high precision for the oil well with the production above $1 \mathrm{~m}^{3} /$ day and the stratigraphic curve of flow conditions with exponential regularity. However, for the extension of oil production is less than $1 \mathrm{~m}^{3} /$ day oil wells, the error is very large and prediction of the open-well time and shut-down time are not accurate enough.

Linear Regress Model. For ultra-low permeability reservoirs, the time when well is opened and shut down is related to inflow performance relationship of oil well, formation parameters (such as permeability) and production parameters (such as liquid production capacity). Therefore, linear regress model can be used. Firstly, model parameter is regressed toward to adverse direction in accordance with the time predicted by other methods when well is opened and shut down. Next, the time when other well is opened and shut down in the block would be indicated by taking advantage of the model [10].

Formation parameters are required in the method. However, the method is not fit for low-yield and inter-pumping wells of Yanchang oilfield due to the limitations that the obvious deviation of formation parameters, principal parameter chose and numbers of terms of polynomial adopted have some experiential ingredients, which lead to the evident deviation of the time when other well is opened and shut down.

Integral Model. Integral model bases on the data of oil well whose liquid level height is continuously measured to ensure the intermittent cycle of oil well. In condition that output of oil well is invariable, according to the liquid level height continuously measured at the time when open-well time and shut-down time, by predicting the condition of fluid from well bottom and the condition of oil-well pump extraction the method could construct integral equation indicated the balance between provision and extraction of oil well. Solving the equation could obtain the optimal open-well time and shut-down time. The advantage of this method is obvious error from the time of discontinuous oil well owing to acquire formation parameter is eliminated.

Prediction of liquid level rising based on the test data of bottom-hole pressure, refer with Eq. 1, P is the bottom-hole pressure, $\rho_{\mathrm{L}}$ is the density of the liquid in the wellbore, $\mathrm{g}$ is the acceleration of gravity, and $\mathrm{hf}$ is the distance from the bottom of the well.

$$
h_{f}=\frac{P}{\rho_{L} g}
$$

Figure 1 shows the liquid level rise curve after shut-down; $M$ is the stop-off point. According to the time difference between the adjacent two points in the curve and the height difference of the liquid level, the bottom-hole flow q and pressure $\mathrm{P}$ can be calculated, refer with Eq. 2, D is casing inside diameter, $\mathrm{d}$ is tubing diameter.

$$
q=\frac{\frac{\pi}{4}\left(D^{2}-d^{2}\right) \Delta h}{\Delta t}
$$

According to the above formula, calculating a series of point can map the formation flow-time curve, the bottom-hole flowing pressure-time curve, the IPR curve.

According to the curve when the liquid level is decline after well opening again, calculating the pump efficiency $\eta p(t)$ of each time under different liquid level height, refer with Eq. 3, Ap is the plunger area of pumping unit, $\mathrm{S}$ is the stroke of pumping motor, $\mathrm{n}$ is the stroke frequency, $\operatorname{qr}(\mathrm{t})$ is the formation flow.

$$
\eta_{p}(t)=\frac{\frac{\pi}{4}\left(D^{2}-d^{2}\right) \Delta h+q_{r}(t) \Delta t}{A_{p} \operatorname{Sn} \Delta t}
$$




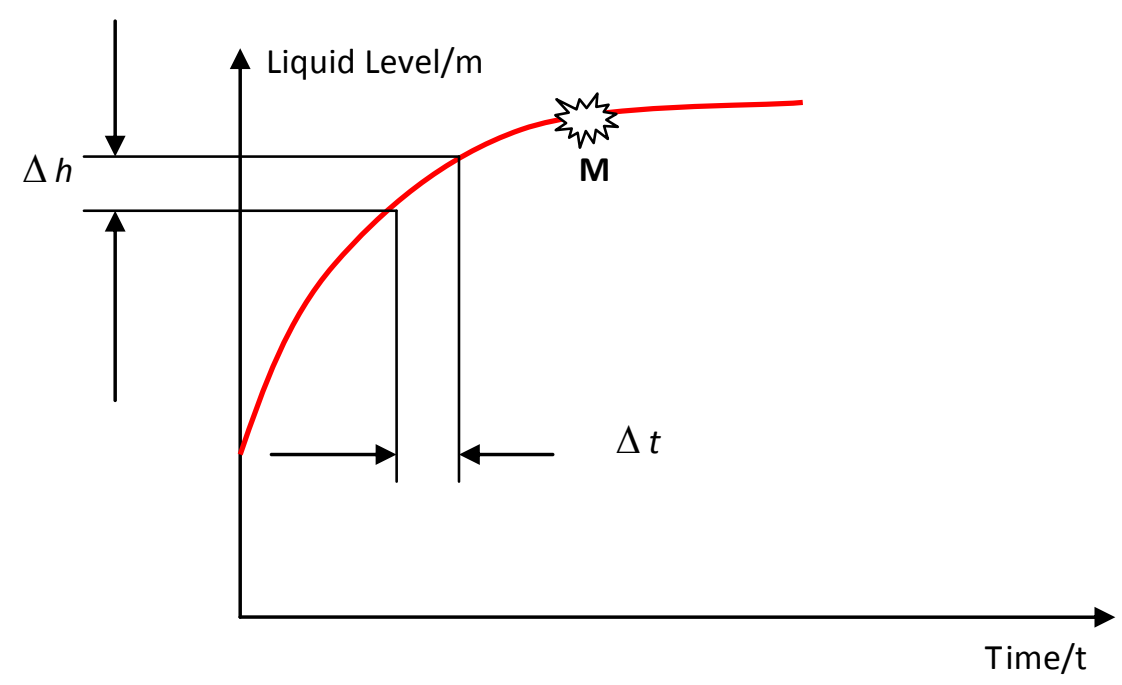

Figure 1. Liquid level rise curve

The Calculation of Open-Well Time. If $\mathrm{M}$ points is the highest liquid level position, start to open well from this point, as shown in figure 1, the calculation of open-well time refer with Eq. 4, T is well open-well time; $\mathrm{q}_{1}(\mathrm{t})$ is the annular flow of oil jacket, $\mathrm{H}$ is the difference of the highest level and the minimum level.

$$
\int_{0}^{T} \frac{A_{p} S n}{60} \eta_{p}(t) d t=\int_{0}^{T} q_{1}(t) d t+\int_{0}^{T} q_{r}(t) d t
$$

Solving the above equation can get open-well time T, the integral type is used by the method of numerical difference, it is easy to implement through the program.

The Calculation of Shutdown Time. The key to shut-down time calculation is to ensure the M point in figure 1, preliminary determination value can be ensured by the slope of a curve point in figure 1. For some curves which are not monotonically rising, as well as there is the case of the inflection point, the initial value may be determined firstly, refered with Eq.5.

$$
k=\frac{d q}{d t}
$$

When the slope of $\mathrm{k}$ value is greater than a critical value, shut-down the wells.

The Field Test. Qili Village Oil Production Plant is a typical ultra-low permeability reservoir in Yanchang Oilfield, the liquid supply capacity of the block is poor, the application of the inter-pumping well is also gradually increasing.

In order to determine the best shut-down time of the inter-pumping prediction model, the pressure of the well can be tested.

The basic data of well Du 131-8 Qili Village oil production plant of Yanchang Oilfield is as follow: the pump setting is $591.8 \mathrm{~m}$, the pump diameter is $44 \mathrm{~mm}$, the length of stoke is $1.2 \mathrm{~m}$ and the stroke frequency is $7 \mathrm{~min}$.

The pressure test curve of well $\mathrm{Du} 131-8$ is as fig 2 . The curve is composed of 4 sections. The first section is the first 61 hours of oil pumping (the inside wellbore liquid level changing curve with pumping the oil to the ground when well is open). The second section is the curve of pressure rise until 221 hours (the liquid level height when well has been shut off). The third section is the well opening curve until 238 hours (the liquid level is decline when well is open). The fourth section is oil pimping curve until 310 hours (the inside wellbore liquid level changing curve when well is open). 


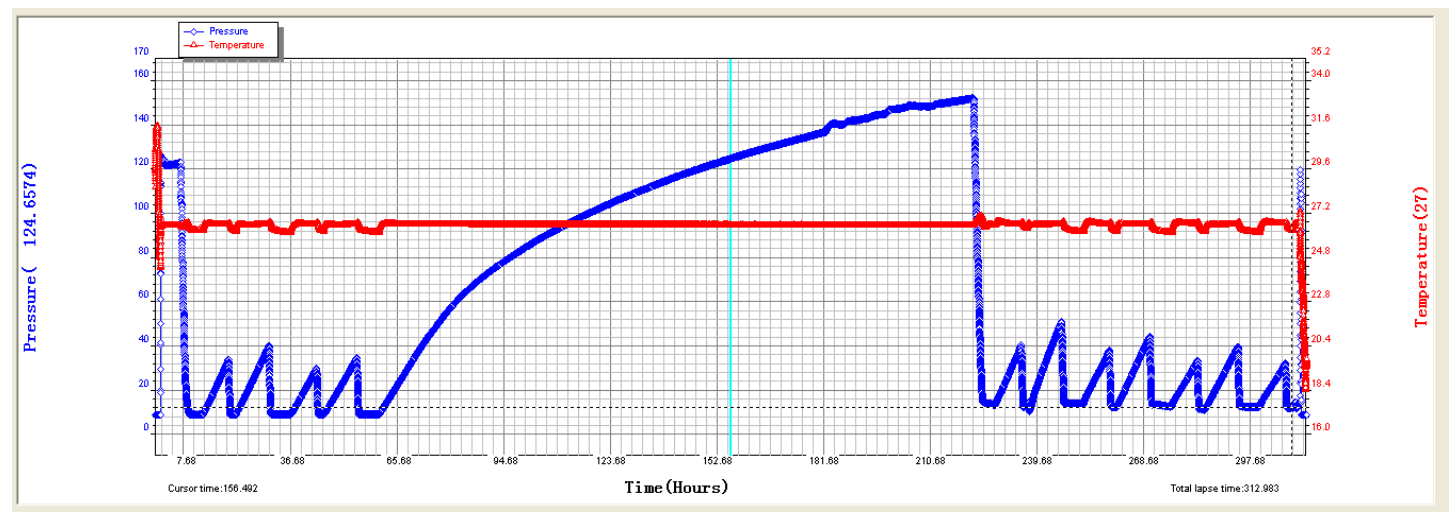

Figure 2. Well Du 131-8 well pressure test curve

By analyzing the second section of pressure rise curve, the rising height of the oil well, the formation flow-time curve, the bottom-hole flowing pressure-time curve and the IPR curve are obtained. By analyzing the pressure rise curve of the third section of fig 2, the pump efficiency curve is obtained. On this basis, put the key point $\mathrm{M}$ in different positions and corresponds to a series of liquid height, shut-off time, open well time and production data, refer with Table 1.

Table 1 Well Du 131-8 interval cycle forecasting

\begin{tabular}{|c|c|c|c|c|}
\hline $\begin{array}{c}\text { M point Liquid } \\
\text { Level }[\mathrm{m}]\end{array}$ & $\begin{array}{c}\text { Close Well } \\
\text { Time }[\mathrm{hr}]\end{array}$ & $\begin{array}{c}\text { Open Well } \\
\text { Time }[\mathrm{hr}]\end{array}$ & $\left.\begin{array}{c}\text { Single } \\
\text { Production[ }\end{array} \mathrm{m}^{3} / \mathrm{day}\right]$ & $\begin{array}{c}\text { Month Cumulative Production } \\
\text { Fluid Volume }\left[\mathrm{m}^{3} / \mathrm{day}\right]\end{array}$ \\
\hline 81 & 69.6 & 6.8 & 0.639 & 6.023 \\
\hline 69.4 & 50.7 & 5.9 & 0.548 & 6.963 \\
\hline 57.8 & 36.1 & 4.9 & 0.456 & 8.02 \\
\hline 46.3 & 24.7 & 3.9 & 0.365 & 9.197 \\
\hline 34.7 & 16.8 & 3 & 0.274 & 10.438 \\
\hline 23.1 & 10.6 & 2 & 0.183 & 10.42 \\
\hline 11.6 & 5.3 & 1 & 0.091 & \\
\hline
\end{tabular}

The results show that the optimal open-well time and the shut-down time of well $\mathrm{Du} 131-8$ to reach the maximum potential of formation are 2 hours and 10.6 hours, which can be used to determine the scientific inter-pumping system.

By using the inter-pumping prediction model of the integral method, the single-well field test was carried out and applied in the Qili Village production plant. After optimizing, the pumping time ranged from 8 hours to 5 hours on average, and single well' s electricity-saving is about 7.5 degrees / day, the rate of electricity-saving is $37.5 \%$. There is about 5770 oil production wells in Qili Village production plant, which is expected to save about 15.79 million $\mathrm{kWh}$, and about 11.05 million yuan.

\section{Conclusion}

According to the geologic characteristics of Yanchang oilfield, it is found that the inter-pumping prediction model of the integral method is more suitable for low-yield and low-efficiency wells of Yanchang oilfield through pressure test.

After the optimization of the inter-pumping system, the Qili Village production plant field test found that Stratigraphic potential can be better played, the energy-saving effect is more obvious and the comprehensive benefits is better.

In actual production and application, it is necessary to take into account the actual situation of oil well production equipment and management (for example, oil loss in the wellbore during the 
shutdown period) and appropriately prolong the pumping time and determine the best inter-pumping system.

\section{References}

[1] H. Liu, J.S. Gao and X. Y. Wang, Research on Reasonable Intermittent Pumping System of Oil Pumping Well, J. Drilling \& Production Technology, Vol.22 (2000) No. 1, p.69-72. In Chinese.

[2] X. M. YU, G Z. He and Y. L. Jin, Study on Rationality of Intermitten Pumping System for Pumping Well, J. Petroleum Geology \& Oilfield Development in Daqing. Vol. 25 (2006) No. 4, p.78-79. In Chinese.

[3] D. Y. Zhou and L. Zheng, A New Approach for Determining the Reasonable Intermittent Pumping Period for Low Efficiency Well, J. Drilling \& Production Technology. Vol. 26 (2003) No. 1, p.46-49. In Chinese.

[4] Y. Z. Xiang and G. J. Liang, Development And Application of Pump-Off Controlling In The Swabbing Well, J. Drilling \& Production Technology. Vol. 26 (2004) No. 6, p.68-70. In Chinese.

[5] L. G. Jones.and J. W. Waltz, Estimating Skin Effect in a Partially Completed Damaged Well, JPT, (1971), p.249-253.

[6] M. B. Standing, A Pressure-Volume-Temperature Correlation for Mixtures of California Oils and Gases, Drill and Prod, Pract. API. (1947), p. 275.

[7] R. K. Guthrie and M. H. Greenberger, The Use of Multiple Correlation Analysis for Interpreting Petroleum Engineering Data, Drill and Prod. Prac. API (1955), p.130-137.

[8] S. F. Dang, Y. G. Liu and Z. G. Li, Grey Syetem Theory And Its Application, Beijing Science Press (2010), p.146-149. In Chinese.

[9] J. L. Li and R. Q. Liao and X.C. Chen, Gray Prediction of Pumping Period between Pumping Wells, J. Fault-Block Oil \& Gas Field. Vol. 19 (2012) No.5, p.634-637. In Chinese.

[10] Pingtian Fan, Study and Application of Interval Determination Method in Low Permeability Reservoir, D, Xi An ShiYou University, (2013). In Chinese. 